\title{
AgNPs Modified Glass Carbon Electrode Prepared with Gelatin as an Additive for Hydrogen Peroxide Sensor
}

\author{
Yuepeng Guan ${ }^{1, \&}$, Xiaogang Sun ${ }^{1, \&}$, Li Yin $^{1}$, Xianghui Hao ${ }^{2}$, Shangwei Guo ${ }^{2, *}$, Yaqin Huang ${ }^{1, *}$ \\ ${ }^{1}$ State Key Laboratory of Chemical Resource Engineering, Beijing Laboratory of Biomedical \\ Materials, Beijing University of Chemical University of Chemical Technology \\ Beijing 100029, People's Republic of China. \\ ${ }^{2}$ Dong E E Jiao Co.,Ltd., E-Jiao Street NO.78, Dong'e County, 252201 Shandong province, People's \\ Republic of China. \\ *E-mail: huangyq@mail.buct.edu.cn; guosw@dongeejiao.com \\ ${ }^{\&}$ These authors contributed equally to this work and should be considered co-first authors.
}

doi: $10.20964 / 2018.08 .43$

Received: 19 August 2017 / Accepted: 6 November 2017 / Published: 5 July 2018

A method which was simple, cost effective and environmental friendly was employed for the synthesis of $\mathrm{Ag}$ nanoparticle (AgNP) with gelatin as a multifunctional additive. The hydrogen peroxide $\left(\mathrm{H}_{2} \mathrm{O}_{2}\right)$ non-enzyme sensor was further fabricated using the mixture of the AgNPs with gelatin and fish-scalebased hierarchical lamellar porous carbon(FHLC). And its electrochemical behavior and stability was analyzed by $\mathrm{CV}$, electrochemical impedance spectroscopy and amperometric I-t curve. In the result, the sensor exhibited an excellent response to the $\mathrm{H}_{2} \mathrm{O}_{2}$, and the detection limit was $0.6 \mu \mathrm{M}$ with the linear response ranging from $0.2 \mathrm{mM}$ to $12.3 \mathrm{mM}\left(\mathrm{R}^{2}=0.999\right)$. In addition, it exhibited good long term stability and anti-interference capability.

Keywords: Gelatin, Ag nanoparticle, Hydrogen peroxide, Electrochemical non-enzyme sensor

\section{FULL TEXT}

(C) 2018 The Authors. Published by ESG (www.electrochemsci.org). This article is an open access article distributed under the terms and conditions of the Creative Commons Attribution license (http://creativecommons.org/licenses/by/4.0/). 